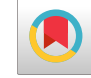

\title{
Association Between Serum Nitric Oxide Level and Changes in Thyroid Function Test in a Population-based Study: Tehran Thyroid Study Participants (TTS)
}

\author{
Behnaz Ghazisaeidi (iD) ${ }^{1}$, Farzaneh Sarvghadi $\mathbb{( D}^{2}{ }^{2}$, Asghar Ghasemi (iD) ${ }^{3}$, Maryam Tohidi ${ }^{4}$, Fereidoun \\ Azizi $^{1}$ and Atieh Amouzegar ${ }^{1, *}$ \\ ${ }^{1}$ Endocrine Research Center, Research Institute for Endocrine Sciences, Ayatollah Taleghani Hospital, Shahid Beheshti University of Medical Sciences, Tehran, Iran \\ ${ }^{2}$ School of Medicine, Ayatollah Taleghani Hospital, Shahid Beheshti University of Medical Sciences, Tehran, Iran \\ ${ }^{3}$ Endocrine Physiology Research Center, Research Institute for Endocrine Sciences, Shahid Beheshti University of Medical Sciences, Tehran, Iran \\ ${ }^{4}$ Prevention of Metabolic Disorders Research Center, Research Institute for Endocrine Sciences, Shahid Beheshti University of Medical Sciences, Tehran, Iran \\ "Corresponding author: Endocrine Research Center, Research Institute for Endocrine Sciences, Ayatollah Taleghani Hospital, Shahid Beheshti University of Medical Sciences, \\ Tehran, Iran. Email: amouzegar@endocrine.ac.ir
}

Received 2020 September 19; Revised 2020 December 20; Accepted 2021 January 18.

\begin{abstract}
Background: Nitric oxide (NO) plays a key role in thyroid function regulation through the inhibition of iodide (I) uptake at the thyroidal sodium-iodide symporter (NIS) and impacts on the thyroid vascularity and blood flow.

Objectives: This study aimed to evaluate the association between serum NO metabolites (NOx) and thyroid-stimulating hormone (TSH), free thyroxin (FT4), and anti-thyroid peroxidase (TPOAb) changes. Also, it aimed at evaluating the correlation between serum NOx and the incidence of clinical hypothyroidism, characterized by elevated TSH level and decreased FT4 concentration, and subclinical hypothyroidism, characterized by mildly elevated TSH level despite FT4 concentration within the normal range, over three years of follow-up.

Methods: This study included 1,137 participants of the Tehran Thyroid study (TTS), aged $>20$ years old, for whom data on serum TSH, FT4, and TPOAb in the third and fourth phases, and serum NOx in the third phase were available. Changes in TSH $(\Delta$ TSH), FT4 ( $\Delta$ FT4), and TPOAb $(\triangle \mathrm{TPO})$ between the third and fourth phases were calculated, and the associations between serum NOx and $\Delta \mathrm{TSH}, \Delta \mathrm{FT} 4$, and $\triangle$ TPOAb were assessed after multivariable adjustment using linear regression analysis.

Results: No significant association was found between serum NOx and $\Delta \mathrm{TSH}, \Delta \mathrm{FT} 4$, and $\Delta \mathrm{TPOAb}$ after the multivariable adjustment; neither was any observed in TPOAb split groups after multivariable adjustment. No significant association was found between serum NOx tertiles and clinical and subclinical hypothyroidism incidence in the fourth phase of TTS.

Conclusions: There was no association between serum NOx levels and changes in TSH, FT4, and TPOAb and clinical and subclinical hypothyroidism incidence.
\end{abstract}

Keywords: Thyroxin, Nitric Oxide, Tehran Thyroid Study, Thyrotropin

\section{Background}

Nitrate is a competitive inhibitor of iodide (I) uptake at the thyroidal sodium-iodide symporter (NIS)(1). Nitrate, nitrite, and nitric oxide (NO) are the oxidized species of nitrogen available for biological uptake (2). Green leafy vegetables contain nitrate, and it is also added to foods as a preservative. Owing to the use of nitrate as an agricultural fertilizer and another atmospheric release of nitrogen oxides, environmental nitrogen emissions have increased enormously (3), leading to an increase in the nitrogen concentrations of surface waters as a potential water pollutant (1). NO is produced endogenously from L- arginine by NO synthases (NOS) enzyme family, mainly in vascular endothelial cells $(4,5)$. Thyroid hormones (THs) influence endothelium and directly rise NO production in vascular smooth muscle cells through the phosphatidylinositol 3-kinase/protein kinase B (PI3K/Akt) signaling pathway $(5,6)$. Direct measurement of this ubiquitous free radical signaling molecule is impossible due to its short halflife $(<0.1 \mathrm{~s})$ (7). Hence, NO metabolites (nitrite + nitrate $=$ NOx) are measured as indirect markers of serum NO synthesis in vivo $(8,9)$. Recent evidence shows the role of NO in the regulation of thyroid function, vascularity and blood flow $(10,11)$. Most of the studies focused on the disrupt- 
ing effects of nitrate on the thyroid axis have considered diet and drinking water nitrate level rather than serum NOx concentration (12-14). In limited low sample size human studies, serum NOx concentration measurement in subjects with thyroid dysfunction reveals controversial results $(5,15-19)$. As far as we know, however, few studies indicate the correlation between serum NOx and changes in THs in an epidemiologic setting. Also, there is increasing evidence on the beneficial effects of high nitrate diets on hypertension control, diabetes mellitus management, etc. (20-23). Assessment of probable side effects of nitrate on human organs would be invaluable.

\section{Objectives}

Among the studies on nitrate as a thyroid disrupter, few have focused on serum nitrate level; therefore, the goal of the present study was to evaluate the correlation between serum NOx level and changes in free thyroxine $(\Delta \mathrm{FT} 4)$, thyroid-stimulating hormone $(\Delta \mathrm{TSH})$ and antithyroid peroxidase antibodies ( $\triangle \mathrm{TPOAb})$ in a populationbased cohort study.

\section{Methods}

\subsection{Subjects}

Tehran Thyroid study (TTS) is a cohort study being performed within the foundation of Tehran Lipid and Glucose study (TLGS). TLGS participants were a representative sample of Tehran (capital of Iran) population who were followed from 1999 during five phases and data on their smoking habits, radioiodine exposure, thyroid surgery, and thyroxin or anti-thyroid medications usage were collected $(24,25)$. This study included 1,971 participants over 20 years old from the third phase of TTS, whose data on serum NOx from the third phase and TSH, FT4, and TPOAb from the third and fourth phases were available. Members using thyroid and anti-thyroid drugs $(\mathrm{n}=100)$, radioactive iodine $(n=1)$, pregnant women $(n=23)$, those with hospitalization history during the past three months $(\mathrm{n}=$ $69)$, chronic diarrhea $(n=35)$, weight loss $(n=67)$, malignancy $(n=5)$, estimated glomerular filtration rate $<60$ $\mathrm{ml} / \mathrm{min} / 1.72 \mathrm{~m}^{2}$, and missing data $(\mathrm{n}=13)$ in the third and fourth phases of TTS were excluded. Finally, 1,137 participants (515 men and 622 women) were included in the study (Figure 1). We calculated TSH, FT4, and TPOAb changes from the third to fourth phase and then evaluated the correlation between the third phase serum NOx level and thyroid function test changes.

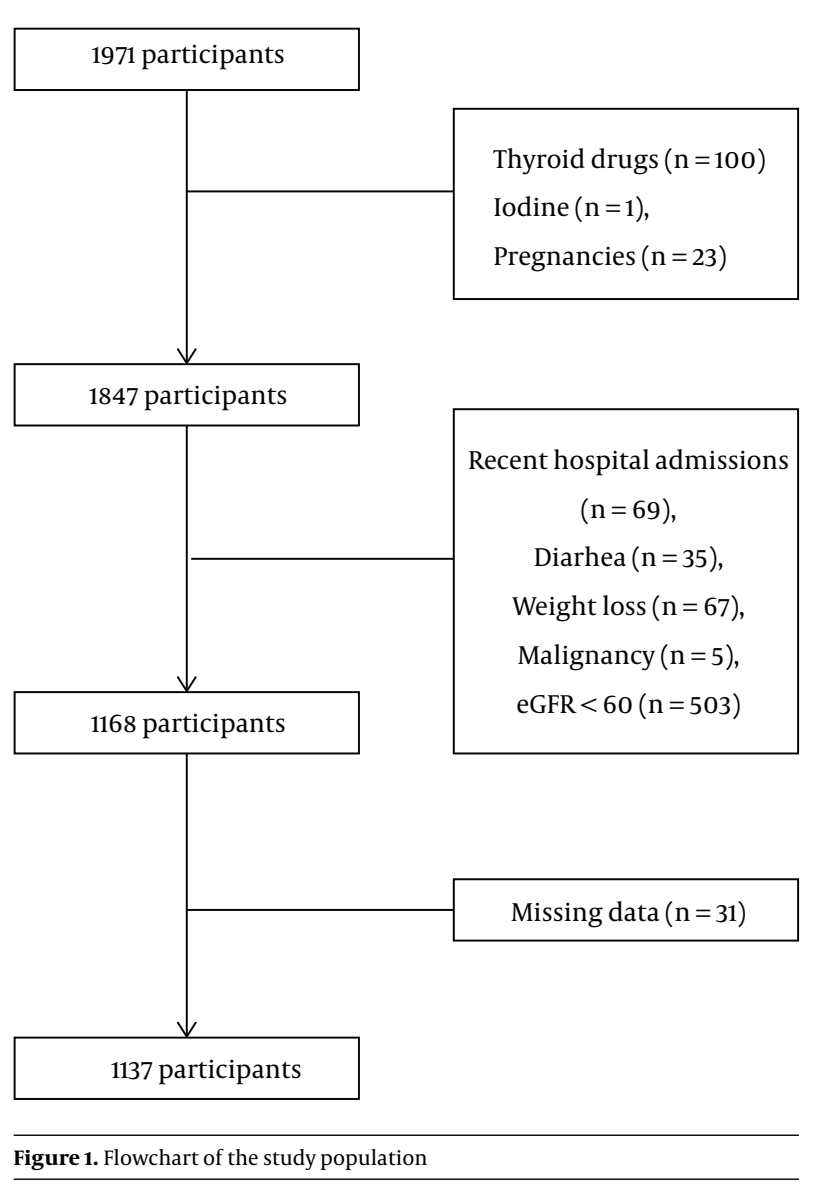

Written informed consent was received from all contributors, and the Ethics Committee of the Research Institute for Endocrine Sciences approved this study.

\subsection{Definition of Terms}

Hyperthyroidism was defined as TSH $<0.324 \mathrm{mIU} / \mathrm{L}$ and FT4 $>19.95 \mathrm{pmol} / \mathrm{L}$, hypothyroidism as TSH $>5.06$ mIU/L and FT4 $<11.71 \mathrm{pmol} / \mathrm{L}$, and subclinical hypothyroidism as TSH $>5.06 \mathrm{mIU} / \mathrm{L}$ and $11.71 \mathrm{pmol} / \mathrm{L}<\mathrm{FT} 4<19.95$ $\mathrm{pmol} / \mathrm{L}(26)$. TPOAb+ were men with TPOAb $>32 \mathrm{IU} / \mathrm{ml}$ and women with TPOAb $>35 \mathrm{IU} / \mathrm{mL}$ (27). History of cardiovascular disease (CVD) contained a history of heart surgery, myocardial infarction, angioplasty, a history of coronary care unit hospitalization, and cerebrovascular attack. Smoking was described as smoking one cigarette per day or more, or water-pipe use. Menopausal status was defined as no menstrual bleeding in the last 12 months.

\subsection{Anthropometric, Clinical, and Laboratory Measurements}

The method of data collection in the TTS has been mentioned in detail previously (25). Waist circumference (WC) 
and hip circumference (HC) were measured according to the standard TTS protocols. A standardized mercury sphygmomanometer was used for blood pressure (BP) measurement after a 15-minute relaxation in a sitting position. Blood sampling was performed after $12 \mathrm{~h}-14 \mathrm{~h}$ overnight fasting. Samples were kept at $-20^{\circ} \mathrm{C}$ until the biochemical measurements were done.

TPOAb was measured by immunoenzymometric assay (IEMA-Monobind, Costa Mesa, CA, USA) using the Sunrise ELISA reader (Tecan Co., Salzburg, Austria); inter and intraassay CVs were $4.2 \%$ and $3.9 \%$, respectively. Serum TSH and free $\mathrm{T} 4$ levels were quantified by the electrochemiluminescence immunoassay (ECLIA) method, using commercial kits on the Cobas e 411 analyzer (Roche Diagnostics $\mathrm{GmbH}$, Mannheim, Germany). Inter- and intra-assay CVs were $4.6 \%$ and $1.4 \%$ for $\mathrm{TSH}$, and $3.3 \%$ and $1.3 \%$ for free $\mathrm{T} 4$, respectively. Serum NOx level was quantified by the Griess method (28), which has been validated in our laboratory (29). In brief, serum was deproteinized using zinc sulfate $(15 \mathrm{mg} / \mathrm{mL})$ and centrifuged. Then $100 \mu \mathrm{L}$ of the supernatant and $100 \mu \mathrm{L}$ vanadium (III) chloride $\left(\operatorname{Ardrich}^{\circledR}\right)(8$ $\mathrm{mg} / \mathrm{mL}$ ) were conveyed to a microplate well to reduce nitrate to nitrite (30). After Griess reagents addition and 30 minutes of incubation at $37^{\circ} \mathrm{C}$, the absorbance was measured by the enzyme-linked immunosorbent assay (ELISA) reader (Tecan Co., Salzburg, Austria) at $540 \mathrm{~nm}$. The linear standard curve established by $0-100 \mu \mathrm{M}$ sodium nitrate was used to define serum NOX level. Inter- and intraassay coefficients of variation (CV) were $5.2 \%$ and $4.4 \%$, respectively. The enzymatic colorimetric method was used for fasting plasma glucose measurement by the glucose oxidase kit (Pars Azmoon Inc., Tehran, Iran); inter and intraassay CVs were both $2.2 \%$. Additionally, enzymatic colorimetric methods were used for triglyceride (TG) and total cholesterol (TC) measurement with glycerol phosphate oxidase and cholesterol esterase and cholesterol oxidase, respectively. TG and TC kits (Pars Azmoon Inc., Tehran, Iran) were used. Inter-and intra-assay CVs were $1.6 \%$ and $0.6 \%$ for TG and $2.0 \%$ and $0.5 \%$ for TC, respectively. Serum creatinine was quantified, using the photometric Jaffe method (Pars Azmoon Inc., Tehran, Iran). Inter- and intra-assay CVs were $3.1 \%$ and $2.2 \%$, respectively. Moreover, eGFR was calculated using the following formula (31): eGFR $=186 \times($ serum $\mathrm{Cr}$ )$1.154 \times$ (age)-0.203 $\times(0.742$ if female $)$.

\subsection{Statistical Analysis}

Qualitative data are presented as number and percentage. Normal distribution of the variables was evaluated using the Kolmogorov-Smirnov test. Quantitative data with non-normal distribution (creatinine, TG, and NOx) are showed as median and Interquartile range (IQR), while those with normal distribution are shown as mean \pm standard deviation(SD). The differences in quantitative normal variables were evaluated by t-test, for non-normal variables using Mann-Whitney U-test, and for qualitative variables using chi-square test between men and women. Spearman's correlation coefficients were computed to quantify the association between serum NOx and $\Delta \mathrm{TSH}, \Delta \mathrm{FT} 4$, and $\triangle T$ TPOAb. Association between serum NOx and $\Delta \mathrm{TSH}$, $\triangle$ FT4 and $\triangle T$ TPOAb as well as between serum NOx tertiles and $\triangle \mathrm{TSH}, \Delta \mathrm{FT} 4$, and $\triangle \mathrm{TPOAb}$ in men and women was evaluated using linear regression analysis. The association between serum NOx and $\triangle \mathrm{TSH}$ and $\triangle \mathrm{FT} 4$ in TPOAb+ and TPOAb- men and women were also evaluated. We adjusted variables with a P-value for entry $(\mathrm{PE})<0.2$ in the univariate analysis. The association between serum NOx level and the incidence of clinical and subclinical hypothyroidism in the fourth phase of TTS, which occurred in euthyroid participants of the third phase, was evaluated by logistic regression analysis. Two-tailed P-values $<0.05$ were considered statistically significant. Owing to the differences in thyroid hormone levels and serum NOx in men and women, the data of these two groups were analyzed separately. The data were analyzed using SPSS (version 20.0) for windows.

\section{Results}

The characteristics of the study participants are represented in Table 1. Men, in comparison to women, were younger, had significantly higher levels of SBP, TG, FBS, Cr, WC, Waist/Hip Ratio (W/H Ratio), while lower values of HC. At baseline, 1,029 (90.7\%) participants were euthyroid that TSH, FT4, and TPOAb were $1.7(1.1$ - 2.6) $\mathrm{mIU} / \mathrm{L}, 15.3 \pm 2.7$ $\mathrm{pmol} / \mathrm{L}$, and 4.8 (2.9 - 9.3) IU/mL, respectively. Moreover, serum NOx was $30.71 \pm 22.17 \mu \mathrm{mol} / \mathrm{L}$.

No correlations were found between serum NOx and $\Delta \mathrm{TSH}(\mathrm{P}=0.350$ in men and $\mathrm{P}=0.142$ in women); serum NOx and $\Delta \mathrm{FT} 4(\mathrm{P}=0.723$ in men and $\mathrm{P}=0.557$ in women $)$. Also, there was no correlation between serum NOx and $\triangle \operatorname{TPOAb}(\mathrm{P}=0.188$ in men and $\mathrm{P}=0.734$ in women $)$ after multivariable adjustment after three years of follow-up (Table 2). This study showed no association between serum NOx tertiles and $\triangle \mathrm{TSH}, \triangle \mathrm{FT} 4$ and $\triangle \mathrm{TPOAb}$ in men and women before and after multivariable adjustment (data not shown). We repeated our analysis in TPOAb+ and TPOAb- participants separately and found no association before and after multivariable adjustment (Table 2).

Out of all euthyroid participants in the third phase, 10 subjects (0.94\%) were diagnosed as clinical hypothyroid 


\begin{tabular}{|c|c|c|c|c|}
\hline Parameters & Total $(\mathrm{N}=1137)$ & $\operatorname{Men}(N=515)$ & Women $(N=622)$ & P-Value $^{b}$ \\
\hline Age, $y$ & $41.7 \pm 12.7$ & $43.0 \pm 13.3$ & $40.6 \pm 12.1$ & 0.001 \\
\hline History of CVD, \% & $34(3.0)$ & $27(5.2)$ & $7(1.1)$ & $<0.001$ \\
\hline Menopausal status, \% & & & $188(30.2)$ & \\
\hline Smoking, \% & $268(23.6)$ & $237(46.0)$ & $31(5.0)$ & $<0.001$ \\
\hline Using medication, \% & $296(26.0)$ & $117(22.7)$ & $179(28.8)$ & 0.021 \\
\hline Systolic blood pressure, mm Hg & $114.4 \pm 17.4$ & $119.1 \pm 16.0$ & $110.6 \pm 17.5$ & $<0.001$ \\
\hline WC, $\mathbf{c m}$ & $91.1 \pm 12.4$ & $95.4 \pm 10.3$ & $87.5 \pm 12.9$ & $<0.001$ \\
\hline $\mathrm{HC}, \mathrm{cm}$ & $101.2 \pm 8.6$ & $99 \pm 6.9$ & $102.9 \pm 9.4$ & $<0.001$ \\
\hline $\mathrm{W} / \mathrm{H}$ ratio & $0.89 \pm 0.09$ & $0.96 \pm 0.06$ & $0.84 \pm 0.08$ & $<0.001$ \\
\hline BMI, $\mathrm{kg} / \mathrm{m}^{2}$ & $27.3 \pm 4.6$ & $26.9 \pm 4.3$ & $27.6 \pm 4.9$ & 0.005 \\
\hline \multicolumn{5}{|l|}{ Thyroid status } \\
\hline Euthyroid, \% & $1029(90.7)$ & $484(94.0)$ & $545(87.6)$ & 0.421 \\
\hline Hypothyroid, \% & $20(1.8)$ & $4(0.8)$ & $16(2.6)$ & 0.211 \\
\hline Subclinical hypothyroid,\% & $62(5.5)$ & $17(3.3)$ & $45(7.2)$ & 0.252 \\
\hline Hyperthyroid, \% & $9(0.8)$ & $3(0.6)$ & $6(1.0)$ & 0.534 \\
\hline Subclinical hyperthyroid, \% & $15(1.3)$ & $7(1.4)$ & $8(1.3)$ & 0.865 \\
\hline $\mathrm{TSH}, \mathrm{mIU} / \mathrm{L}$ & $1.7(1.1-2.6)$ & $1.5(1.0-2.2)$ & $1.9(1.2-3.1)$ & $<0.001$ \\
\hline FT4, pmol/L & $15.3 \pm 2.7$ & $16.3 \pm 2.9$ & $14.7 \pm 2.2$ & 0.112 \\
\hline TPOAb, IU/mL & $4.8(2.9-9.3)$ & $4.4(2.8-8.3)$ & $5.2(3.0-11.8)$ & 0.029 \\
\hline $\mathrm{NOx}, \mu \mathrm{mol} / \mathrm{L}$ & $24(18-34)$ & $25(19-34)$ & $24(17-35)$ & 0.426 \\
\hline Serum triglycerides, $\mathrm{mg} / \mathrm{dL}$ & $130(88-187)$ & $144(103-204)$ & $116.5(79-171)$ & $<0.001$ \\
\hline Total cholesterol, mg/dL & $188.7 \pm 39.0$ & $187.9 \pm 37.2$ & $189.4 \pm 40.5$ & 0.520 \\
\hline Fasting serum glucose, $\mathbf{m g} / \mathbf{d L}$ & $94.5 \pm 26.3$ & $96.4 \pm 28.0$ & $93.0 \pm 24.6$ & 0.029 \\
\hline Serum creatinine, $\mathrm{mg} / \mathrm{dL}$ & $1.0(0.9-1.1)$ & $1.14(1.1-1.2)$ & $0.9(0.9-1.0)$ & $<0.001$ \\
\hline
\end{tabular}

Abbreviations: BMI, body mass index; CVD, cardiovascular disease; FT4, free thyroxin; HC, hip circumference; NOx, serum nitrite + nitrate; TPOAb, thyroid peroxidase antibody; TSH, thyroid-stimulating hormone; WC, waist circumference; W/H R, waist/hip ratio.

${ }^{\mathrm{a}}$ Values are expressed as mean $\pm \mathrm{SD}$ or median (IQR) and categorical variables as percent.

${ }^{\mathrm{b}}$ For continuous variables independent $t$-test and for categorical one chi-square test were used.

and $43(4.04 \%)$ as subclinical hypothyroid in the fourth phase. There was no association between serum NOx tertiles and the incidence of clinical and subclinical hypothyroidism in participants after three years of follow-up (Table 3).

\section{Discussion}

This study showed no association between serum NOx concentration, and $\Delta \mathrm{TSH}, \Delta \mathrm{FT} 4$, and $\Delta \mathrm{TPOAb}$ in a threeyear follow-up. Serum NOx level was within the normal range for the general population in our participants. Neither was any association demonstrated between serum NOx concentration and incidence of clinical and subclinical hypothyroidism in euthyroid participants at the end of the follow-up.

These findings are inconsistent with those of the Bagherpoor et al. (32), in a cross-sectional study conducted on 1,771 participants in the third phase of TTS for evaluating the association between serum NOx concentration and thyroid function tests. This study showed a significant correlation between serum NOx and FT4 in men, and TPOAb in women. These conflicting results may be due to several factors such as differences in the study design and participants. Additionally, unlike the study conducted by Bagherpoor et al. (32), the participants with eGFR $<60 \mathrm{ml} / \mathrm{min} / 1.72$ $\mathrm{m}^{2}$ were excluded from this study since individuals with lower eGFR have higher serum nitrate levels (33) and various thyroid function test abnormalities (34). Some other studies, in which serum NO level was evaluated in hypo- 


\begin{tabular}{|c|c|c|c|c|c|c|}
\hline \multirow{2}{*}{ Parameters } & \multicolumn{3}{|c|}{ Men } & \multicolumn{3}{|c|}{ Women } \\
\hline & $\mathrm{B}(\mathrm{SE})$ & P-Value & R-Square & $\mathbf{B}(\mathrm{SE})$ & P-Value & R-Square \\
\hline \multicolumn{7}{|l|}{$\Delta \mathrm{TSH}$} \\
\hline \multicolumn{7}{|l|}{ Unadjusted } \\
\hline Total & $-0.907(0.970)$ & 0.350 & 0.002 & $4.236(2.884)$ & 0.142 & 0.003 \\
\hline TPOAb+ & $-0.275(1.030)$ & 0.791 & 0.041 & $0.042(1.156)$ & 0.971 & 0.004 \\
\hline TPOAb- & $-0.947(1.047)$ & 0.366 & 0.042 & $4.612(3.290)$ & 0.162 & 0.061 \\
\hline \multicolumn{7}{|c|}{ Multivariable adjusted $^{\mathrm{a}}$} \\
\hline Total & $-0.776(0.966)$ & 0.423 & 0.017 & $4.948(2.919)$ & 0.091 & 0.009 \\
\hline TPOAb+ & $0.250(0.998)$ & 0.603 & 0.143 & $-0.262(1.154)$ & 0.821 & 0.093 \\
\hline TPOAb- & $-0.828(1.043)$ & 0.427 & 0.016 & $5.402(3.275)$ & 0.100 & 0.046 \\
\hline \multicolumn{7}{|l|}{$\Delta$ FT4 } \\
\hline \multicolumn{7}{|l|}{ Unadjusted } \\
\hline Total & $0.025(0.072)$ & 0.723 & $<0.001$ & $-0.014(0.024)$ & 0.557 & 0.001 \\
\hline $\mathrm{TPOAb}+$ & $0.013(0.945)$ & 0.089 & $<0.001$ & $0.001(0.072)$ & 0.984 & $<0.001$ \\
\hline TPOAb- & $0.038(0.019)$ & 0.040 & 0.095 & $-0.018(0.025)$ & 0.483 & 0.031 \\
\hline \multicolumn{7}{|c|}{ Multivariable adjusted $^{\mathrm{a}}$} \\
\hline Total & $0.020(0.071)$ & 0.778 & 0.019 & $-0.024(0.024)$ & 0.312 & 0.012 \\
\hline $\mathrm{TPOAb}+$ & $-0.244(1.013)$ & 0.611 & 0.154 & $-0.011(0.071)$ & 0.873 & 0.067 \\
\hline TPOAb- & $0.036(0.018)$ & 0.053 & 0.024 & $-0.024(0.025)$ & 0.341 & 0.015 \\
\hline \multicolumn{7}{|l|}{$\triangle \mathrm{TPOAb}$} \\
\hline \multicolumn{7}{|l|}{ Unadjusted } \\
\hline Total & $-0.208(0.158)$ & 0.188 & 0.003 & $-0.093(0.273)$ & 0.734 & $<0.001$ \\
\hline $\mathrm{TPOAb}+$ & $0.107(0.994)$ & 0.915 & $<0.001$ & $-0.298(0.402)$ & 0.460 & 0.006 \\
\hline TPOAb- & $-0.208(0.150)$ & 0.166 & 0.004 & $-0.097(0.306)$ & 0.762 & $<0.001$ \\
\hline \multicolumn{7}{|c|}{ Multivariable adjusted $^{\mathrm{a}}$} \\
\hline Total & $-0.202(0.159)$ & 0.205 & 0.006 & $0.013(0.274)$ & 0.961 & 0.015 \\
\hline TPOAb+ & $0.296(0.991)$ & 0.767 & 0.066 & $-0.276(0.394)$ & 0.485 & 0.052 \\
\hline TPOAb- & $-0.208(0.150)$ & 0.166 & 0.004 & $0.023(0.307)$ & 0.941 & 0.020 \\
\hline
\end{tabular}

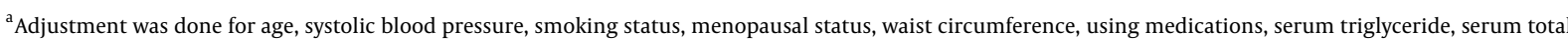
cholesterol, fasting serum glucose, and serum creatinine. TPOAb+: > $32 \mathrm{IU} / \mathrm{mL}$ for men and $>35 \mathrm{IU} / \mathrm{mL}$ for women.

and hyperthyroid individuals, have shown controversial results. Verma et al. (35) showed higher serum NO levels in 50 hypothyroid individuals in India, which was similar to Atta et al. (18) and Coria et al. studies (17) conducted on 60 and 20 hypothyroid cases, respectively. In contrast, other studies showed lower serum NO level (5) or no nitrate changes in hypothyroid patients (15). Results on NO level in hyperthyroid patients are controversial $(15,35)$. All of these studies had small sample sizes and were carried out in different countries with different statuses of iodine sufficiency.

Despite other studies discussed herein, this is a cohort study with a larger sample size designed differently. Some studies were done in iodine-deficient areas, whereas Iran has been an iodine-sufficient area since the year 2000.

In vivo nitrate at a molar concentration of $297 \mu \mathrm{mol} / \mathrm{L}$ corresponds to $50 \%$ inhibition of iodide(I) uptake through human NIS expressing in Chinese hamster ovary cells in a competitive manner (36). The $95 \%$ reference value for serum NOx concentration is $11.5-76.4 \mu \mathrm{mol} / \mathrm{L}$ in men and 10.1 - $65.6 \mu \mathrm{mol} / \mathrm{L}$ in women, which corresponds to $10-15 \%$ inhibition of I uptake with NIS in vivo (30). With respect to $\mathrm{Km}=33.9 \mu \mathrm{mol} / \mathrm{L}$ for I uptake at NIS level and very low serum I concentrations in human $(2-10 \mu \mathrm{g} / \mathrm{L}$ in iodine- 


\begin{tabular}{|c|c|c|c|c|c|c|}
\hline \multirow{2}{*}{ Parameters } & \multicolumn{2}{|c|}{ Clinical Hypothyroidism } & \multicolumn{2}{|c|}{ Subclinical Hypothyroidism } & \multicolumn{2}{|c|}{ Clinical + Subclinical Hypothyroidism } \\
\hline & OR $(95 \% \mathrm{CI})$ & P-Value & $\mathrm{OR}(95 \% \mathrm{CI})$ & P-Value & OR $(95 \% \mathrm{CI})$ & P-Value \\
\hline \multicolumn{7}{|l|}{ Unadjusted } \\
\hline \multicolumn{7}{|c|}{ Tertile 1 (ref) } \\
\hline Tertile 2 & $1.327(0.353-4.983)$ & 0.675 & $1.284(0.637-2.590)$ & 0.485 & $1.300(0.695-2.433)$ & 0.411 \\
\hline Tertile 3 & $0.259(0.029-2.325)$ & 0.227 & $0.686(0.304-1.549)$ & 0.365 & $0.591(0.277-1.260)$ & 0.173 \\
\hline \multicolumn{7}{|l|}{ Adjusted $^{\mathrm{a}}$} \\
\hline \multicolumn{7}{|c|}{ Tertile 1 (ref) } \\
\hline Tertile 2 & $1.468(0.388-5.551)$ & 0.572 & $1.687(0.813-3.498)$ & 0.160 & $1.658(0.866-3.172)$ & 0.127 \\
\hline Tertile 3 & $0.310(0.034-2.811)$ & 0.298 & $0.886(0.383-2.052)$ & 0.778 & $0.747(0.343-1.624)$ & 0.461 \\
\hline
\end{tabular}

Abbreviation: OR, odds ratio.

${ }^{a}$ Adjustment was done for age, systolic blood pressure, serum triglyceride, serum creatinine, waist circumference, smoking status.

sufficient areas like Iran), theoretically, nitrate can block I uptake at the thyroidal sodium-iodide symporter (NIS) in normal nitrate levels in human (36), which is more probable in iodine-deficient areas (1).

According to our results, it seems that serum nitrate at normal levels in humans is not potent enough to reduce TH production in iodine-sufficient areas. Several studies have demonstrated the beneficial effects of high-level nitrate diets such as dietary approaches to stop hypertension (DASH) on the reduction of endothelial dysfunction, cardiovascular treatment (22), hypertension control (21), declining insulin resistance (20), and the improvement of brain perfusion in older adults (23). Moreover, nitratecontaining drugs are widely used for the treatment of cardiovascular diseases. Our results suggest that these treatments have no adverse effects on thyroid function tests if they maintain serum NOx levels within normal range.

Regarding study strengths, to the best of our knowledge, this is one of the few population-based cohort studies evaluating the correlation between serum NOx concentration and $\Delta \mathrm{TSH}, \Delta \mathrm{FT} 4$ and $\Delta \mathrm{TPOAb}$ in more than 1,000 participants over a three-year follow-up. However, we had some limitations: First, we did not assess the nitrate content of participant's diet as an important source for nitrate in humans (37); however, the subjects blood samples were obtained after 12 - 24 hours of overnight fasting and awareness that dietary nitrate had to be removed from the plasma within 12 hours of a meal (38). In addition, the majority of nitrate is produced via enzymatic NO formation from NOS during fasting (39). Second, the history of immune disease, which can affect serum NOx concentration, was not registered (40). Third, since we only had data on serum NO level in the third phase, its changes were not calculated; however, the factors affecting serum NO level such as smoking, BMI, FBS, eGFR, etc. were considered (41). Finally, it seems that three years of follow-up may not be sufficient for the assessment of hypothyroidism incidence.

\subsection{Conclusions}

This study showed no association between serum NOx level and thyroid function tests (TSH, FT4, and TPOAb) changes and no correlation between serum nitrate levels and the incidence of clinical and subclinical hypothyroidism during three years of follow-up. We recommend planning a larger sample size cohort study with longer follow-up, which can better assess the relationship between serum NOx level and the incidence of hypothyroidism and hyperthyroidism. It may also be reasonable to assess this correlation in populations with high serum nitrate levels from iodine-deficient areas.

\section{Acknowledgments}

This article has been extracted from the thesis writing by Behnaz Ghazisaeidi in School of Medicine, Shahid Beheshti University of Medical Sciences (registration no.: 129). The authors wish to thank the laboratory staff of the Research Institute for Endocrine Sciences of Shahid Beheshti University of Medical Sciences and acknowledge Ms. Niloofar Shiva for the critical editing of English grammar and syntax of the manuscript.

\section{Footnotes}

Authors' Contribution: Study concept and design: FA and FS. Analysis and interpretation of data: BG and FS. Drafting of the manuscript: AA and AG. Critical revision of 
the manuscript for important intellectual content: FA, and FS, AA, and SB. Statistical analysis: BG and MT.

Conflict of Interests: The authors report no conflicts of interest. The authors alone are responsible for the content and writing of this article.

Ethical Approval: The Ethics Committee of the Research Institute for Endocrine Sciences approved this study. This study has been performed with the approval of the Human Research Review Committee of the Endocrine Research Center, Shahid Beheshti University, Tehran, Iran. The approval code was IR SBMU.ENDOCRINE.REC.1396.457.

\section{Funding/Support: None.}

Informed Consent: Written informed consent was received from all contributors.

\section{References}

1. Poulsen R, Cedergreen N, Hayes T, Hansen M. Nitrate: An Environmental Endocrine Disruptor? A Review of Evidence and Research Needs Environ Sci Technol. 2018;52(7):3869-87. doi: 10.1021/acs.est.7b06419. [PubMed: 29494771].

2. Billen G, Garnier J, Lassaletta L. The nitrogen cascade from agricultural soils to the sea: modelling nitrogen transfers at regional watershed and global scales. Philos Trans $R$ Soc Lond B Biol Sci. 2013;368(1621):20130123. doi: 10.1098/rstb.2013.0123. [PubMed: 23713121]. [PubMed Central: PMC3682743].

3. Sutton MA, Bleeker A, Howard CM, Erisman JW, Abrol YP, Bekunda M, et al.Our nutrient world. The challenge to produce more food $\&$ energy with less pollution. Centre for Ecology \& Hydrology; 2013.

4. Cymeryng CB, Lotito SP, Colonna C, Cornejo MF, Podestá EJ. Induction of nitric oxide synthase activity in adrenal cells. Endocr Res. 2000;26(4):589-95. doi: 10.3109/07435800009048576. [PubMed: 11196434].

5. Kumar A, Suresh DR, Annam V, Srikrishna R. Significance of early biochemical markers of atherosclerosis in subclinical hypothyroidism patients with normal lipid profile. Int J Biol Med Res. 2012;3(4):2483-6.

6. Carrillo-Sepúlveda MA, Ceravolo GS, Fortes ZB, Carvalho MH, Tostes RC, Laurindo FR, et al. Thyroid hormone stimulates NO production via activation of the PI3K/Akt pathway in vascular myocytes. Cardiovasc Res. 2010;85(3):560-70. doi: 10.1093/cvr/cvp304. [PubMed: 19734167]. [PubMed Central: PMC3031311]

7. Ghasemi A, Zahediasl S, Azimzadeh I, Azizi F. Increased serum nitric oxide metabolites in dysglycaemia. Ann Hum Biol. 2011;38(5):577-82 eng. doi: 10.3109/03014460.2011.575384. [PubMed: 21561301].

8. Ghasemi A, Zahediasl S. Preanalytical and analytical considerations for measuring nitric oxide metabolites in serum or plasma using the Griess method. Clin Lab. 2012;58(7-8):615-24. eng. [PubMed: 22997962]

9. Tsikas D. Analysis of nitrite and nitrate in biological fluids by assays based on the Griess reaction: appraisal of the Griess reaction in the L-arginine/nitric oxide area of research. J Chromatogr B Analyt Technol Biomed Life Sci. 2007;851(1-2):51-70. doi 10.1016/j.jchromb.2006.07.054. [PubMed: 16950667].

10. Fellet AL, Arza P, Arreche N, Arranz C, Balaszczuk AM. Nitric oxide and thyroid gland: modulation of cardiovascular function in autonomic-blocked anaesthetized rats. Exp Physiol. 2004;89(3):30312. doi: 10.1113/expphysiol.2004.027201. [PubMed: 15123566].

11. Colin IM, Nava E, Toussaint D, Maiter DM, vanDenhove MF, Lüscher $\mathrm{TF}$, et al. Expression of nitric oxide synthase isoforms in the thy- roid gland: evidence for a role of nitric oxide in vascular control during goiter formation. Endocrinology.1995;136(12):5283-90. doi: 10.1210/endo.136.12.7588272. [PubMed: 7588272].

12. Gatseva PD, Argirova MD. High-nitrate levels in drinking water may be a risk factor for thyroid dysfunction in children and pregnant women living in rural Bulgarian areas. Int J Hyg Environ Health. 2008;211(56):555-9. doi:10.1016/j.ijheh.2007.10.002. [PubMed:18164247].

13. Gatseva PD, Argirova MD. Iodine status and goitre prevalence in nitrate-exposed schoolchildren living in rural Bulgaria. Public Health. 2008;122(5):458-61. doi: 10.1016/j.puhe.2007.09.001. [PubMed: 18187169].

14. Kilfoy BA, Zhang Y, Park Y, Holford TR, Schatzkin A, Hollenbeck A, et al. Dietary nitrate and nitrite and the risk of thyroid cancer in the NIH-AARP Diet and Health Study. Int J Cancer. 2011;129(1):16072. doi: 10.1002/ijc.25650. [PubMed: 20824705]. [PubMed Central: PMC3016446].

15. Hermenegildo C, Medina P, Peiró M, Segarra G, Vila JM, Ortega J, et al. Plasma concentration of asymmetric dimethylarginine, an endogenous inhibitor of nitric oxide synthase, is elevated in hyperthyroid patients. J Clin Endocrinol Metab. 2002;87(12):5636-40. doi: 10.1210/jc.2002-020905. [PubMed: 12466365].

16. Ozcan O, Cakir E, Yaman H, Akgul EO, Erturk K, Beyhan Z, et al. The effects of thyroxine replacement on the levels of serum asymmetric dimethylarginine (ADMA) and other biochemical cardiovascular risk markers in patients with subclinical hypothyroidism. Clin Endocrinol (Oxf). 2005;63(2):203-6. doi: 10.1111/j.1365-2265.2005.02326.x. [PubMed: 16060915].

17. Coria MJ, Pastrán AI, Gimenez MS. Serum oxidative stress parameters of women with hypothyroidism. Acta Biomed. 2009;80(2):135-9. [PubMed: 19848051].

18. Atta MN, Elessawy R, Deghedy A, Hafez A, Elsherbiny TM. Hashimoto thyroiditis is an independent cardiovascular risk factor in clinically hypothyroid patients. Alexandria J Med. 2019;47(4):267-76. doi: 10.1016/j.ajme.2011.09.004.

19. Bivolarska AV, Maneva AI, Gatseva PD, Katsarova MN. Effect of Nitrates, Thiocyanates and Selenium on the Iron and Iodine Status of Postpartum Women. Folia Med (Plovdiv). 2016;58(3):188-94. doi: 10.1515/folmed-2016-0024. [PubMed: 27760010].

20. Bahadoran Z, Ghasemi A, Mirmiran P, Azizi F, Hadaegh F. Beneficial effects of inorganic nitrate/nitrite in type 2 diabetes and its complications. Nutr Metab (Lond). 2015;12:16. doi: 10.1186/s12986-015-0013-6. [PubMed: 25991919]. [PubMed Central: PMC4436104].

21. Larsen FJ, Ekblom B, Sahlin K, Lundberg JO, Weitzberg E. Effects of dietary nitrate on blood pressure in healthy volunteers. $N$ Engl J Med. 2006;355(26):2792-3. doi:10.1056/NEJMc062800. [PubMed:17192551].

22. Ahluwalia A, Gladwin M, Coleman GD, Hord N, Howard G, KimShapiro DB, et al. Dietary Nitrate and the Epidemiology of Cardiovascular Disease: Report From a National Heart, Lung, and Blood Institute Workshop. J Am Heart Assoc. 2016;5(7). doi: 10.1161/jaha.116.003402. [PubMed: 27385425]. [PubMed Central: PMC5015377].

23. Presley TD, Morgan AR, Bechtold E, Clodfelter W, Dove RW, Jennings $\mathrm{JM}$, et al. Acute effect of a high nitrate diet on brain perfusion in older adults. Nitric Oxide. 2011;24(1):34-42. doi: 10.1016/j.niox.2010.10.002. [PubMed: 20951824]. [PubMed Central: PMC3018552].

24. Azizi F, Rahmani M, Emami H, Mirmiran P, Hajipour R, Madjid M, et al. Cardiovascular risk factors in an Iranian urban population: Tehran lipid and glucose study (phase 1). Soz Praventivmed. 2002;47(6):40826. doi: 10.1007/s000380200008. [PubMed: 12643001].

25. Azizi F, Amouzegar A, Delshad H, Tohidi M, Mehran L, Mehrabi Y. Natural course of thyroid disease profile in a population in nutrition transition: Tehran Thyroid Study. Arch Iran Med. 2013;16(7):418-23. [PubMed: 23808780]. 
26. Amouzegar A, Delshad H, Mehran L, Tohidi M, Khafaji F, Azizi F. Reference limit of thyrotropin (TSH) and free thyroxine (FT4) in thyroperoxidase positive and negative subjects: a population based study. J Endocrinol Invest. 2013;36(11):950-4. doi: 10.3275/9033. [PubMed: 23873252].

27. Amouzegar A, Bakhtiyari M, Mansournia MA, Etemadi A, Mehran L, Tohidi M, et al. Sex- and Age-Specific Reference Values and Cutoff Points for TPOAb: Tehran Thyroid Study. Thyroid. 2016;26(3):458-65. doi: 10.1089/thy.2015.0276. [PubMed: 26650261].

28. Miranda KM, Espey MG, Wink DA. A rapid, simple spectrophotometric method for simultaneous detection of nitrate and nitrite. Nitric Oxide. 2001;5(1):62-71. doi: 10.1006/niox.2000.0319. [PubMed: 11178938].

29. Ghasemi A, Hedayati M, Biabani H. Protein precipitation methods evaluated for determination of serum nitric oxide end products by the Griess assay. JMSR. 2007;2(15):29-32.

30. Ghasemi A, Zahediasl S, Azizi F. Reference values for serum nitric oxide metabolites in an adult population. Clin Biochem. 2010;43(1-2):8994. doi:10.1016/j.clinbiochem.2009.09.011. [PubMed:19782059].

31. Cockcroft DW, Gault MH. Prediction of creatinine clearance from serum creatinine. Nephron. 1976;16(1):31-41. doi: 10.1159/000180580. [PubMed: 1244564].

32. Bagheripuor F, Gharibzadeh S, Ghanbari M, Amouzegar A, Tohidi M, Azizi F, et al. Association between serum nitric oxide metabolites and thyroid hormones in a general population: Tehran Thyroid Study. Endocr Res. 2016;41(3):193-9. doi: 10.3109/07435800.2015.1126844. [PubMed: 26864772].

33. Williams JK, Smallwood MJ, Benjamin N, D'Souza RJ, Shore AC, Winyard PG, et al. Renal nitrate clearance in chronic kidney disease. Nitric Oxide. 2020;97:16-9. doi: 10.1016/j.niox.2020.01.011. [PubMed: 32007629].

34. Srivastava S, Rajput J, Shrivastava M, Chandra R, Gupta M, Sharma R Correlation of Thyroid Hormone Profile with Biochemical Markers of Renal Function in Patients with Undialyzed Chronic Kidney Disease.
Indian J Endocrinol Metab. 2018;22(3):316-20. doi: 10.4103/ijem.IJEM_475_17. [PubMed:30090721]. [PubMed Central: PMC6063181].

35. Verma M, Dahiya K, Ghalaut V, Seth S, Roy P, Basu A, et al. Thyroid disorders and nitric oxide levels. J Sci Med. 2015;5(1):4-8.

36. Tonacchera M, Pinchera A, Dimida A, Ferrarini E, Agretti P, Vitti P, et al. Relative potencies and additivity of perchlorate, thiocyanate, nitrate, and iodide on the inhibition of radioactive iodide uptake by the human sodium iodide symporter. Thyroid.2004;14(12):1012-9. doi: 10.1089/thy.2004.14.1012. [PubMed: 15650353].

37. Baylis C, Vallance P. Measurement of nitrite and nitrate levels in plasma and urine-what does this measure tell us about the activity of the endogenous nitric oxide system? Curr Opin Nephrol Hypertens. 1998;7(1):59-62. doi: 10.1097/00041552-199801000-00010. [PubMed: 9442364].

38. Node K, Kitakaze M, Yoshikawa H, Kosaka H, Hori M. Reversible reduction in plasma concentration of nitric oxide induced by cigarette smoking in young adults. Am J Cardiol. 1997;79(11):1538-41 doi: 10.1016/s0002-9149(97)00189-6. [PubMed: 9185651].

39. Bryan NS, Grisham MB. Methods to detect nitric oxide and its metabolites in biological samples. Free Radic Biol Med. 2007;43(5):645-57. doi: 10.1016/j.freeradbiomed.2007.04.026. [PubMed: 17664129]. [PubMed Central: PMC2041919].

40. Oates JC, Shaftman SR, Self SE, Gilkeson GS. Association of serum nitrate and nitrite levels with longitudinal assessments of disease activity and damage in systemic lupus erythematosus and lupus nephritis. Arthritis Rheum. 2008;58(1):263-72. doi: 10.1002/art.23153. [PubMed: 18163495]. [PubMed Central: PMC2733831].

41. Bahadoran Z, Mirmiran P, Jeddi S, Momenan AA, Azizi F, Ghasemi A The Nitrate-Nitrite-Nitric Oxide Pathway: Findings from 20 Years of the Tehran Lipid and Glucose Study. Int I Endocrinol Metab. 2018;16(4 Suppl). e84775. doi:10.5812/ijem.84775. [PubMed: 30584441]. [PubMed Central: PMC6289293]. 